\title{
The COVID-19 Pandemic and Ethical Challenges Posed by Neoliberal Healthcare
}

\author{
Christopher Ahlbach, $B S^{7}$, Teresa King, $B A^{2}$, and Elizabeth Dzeng, $M D, P h D, M P H^{3,4}{ }_{\odot}$ \\ ${ }^{1}$ School of Medicine, University of California, San Francisco, San Francisco, CA, USA; ${ }^{2}$ California Institute of Integral Studies, San Francisco, CA, USA; \\ ${ }^{3}$ Department of Medicine, Division of Hospital Medicine, University of California, San Francisco, San Francisco, CA, USA; ${ }^{4}$ Philip R. Lee Institute for \\ Health Policy Studies, University of California, San Francisco, San Francisco, CA, USA.
}

J Gen Intern Med 36(1):205-6

DOI: $10.1007 / \mathrm{s} 11606-020-06316-\mathrm{w}$

(c) Society of General Internal Medicine 2020

A s COVID-19 continues to ravage the world, the pandemic has revealed the stark inadequacies of the United States' beleaguered social safety net and health care system, which have predisposed us to a poor emergency response. In addition to the 27.9 million uninsured Americans prior to the pandemic, the economic spillover added 36 million and counting newly unemployed Americans. ${ }^{1}$ COVID-19 has revealed and exacerbated inequalities in US health outcomes and healthcare access which are characteristic of a neoliberal system. Neoliberalism holds that laissez-faire economics result in an optimally organized social system. However, we argue that neoliberal healthcare is fundamentally unethical as healthcare is a human right and not a commodity. Though much thought and research has examined the ways in which the failures of our healthcare system are unethical, the role of neoliberalism has been rarely acknowledged. This gap in scrutiny is worth addressing, as neoliberal economic forces influence if not dictate many dangerous inadequacies with US healthcare, especially in this time of COVID-19.

The term "neoliberalism" refers to a political and economic philosophy of unbridled capitalism popularized in the 1970s and 1980s that favors corporate deregulation, privatization, and austerity (i.e., reducing government spending for social services), and is the dominant economic system in the USA. ${ }^{2}$ In the context of US healthcare, neoliberal policies promote corporate profit through the privatization of systems of healthcare delivery and payment models which transformed a social service into a business. The interests of the private sector (e.g., profit) are prioritized, while the interests of the public (e.g., healthcare and health), whose labor enables that profit, remain secondary.

Received August 11, 2020

Revised September 4, 2020

Accepted October 12, 2020

Published online October 27, 2020
As evidenced by the rapid and effective COVID-19 response seen in countries with socialized healthcare delivery systems such as New Zealand, we can better meet the needs of our patients and improve public health by decoupling our care models from corporate interests. The magnitude of social disruption due to the pandemic offers a rare opportunity to reflect on the ubiquity of neoliberalism, and proactively design a more ethical system. Despite the labor of health workers trying to meet their patients' needs during these unprecedented times, our system is flailing. The neoliberal trade-off of capital for corporations and austerity for the working poor is unethical and ill-suited to the achievement of human rights, including just access to healthcare.

The Universal Declaration of Human Rights states that access to adequate medical care is a human right, and in this the USA is profoundly lacking. Those without insurance have no means of obtaining healthcare outside of entering debt. This violation of human rights leads to morbidity and death. A recent analysis estimated that if every American were to have health insurance, 68,000 deaths would be avoided each year. ${ }^{3}$ The neoliberal healthcare system in the USA was intentionally designed to allow corporate wealth accumulation at the expense of public health, as evidenced by recent reports of enormous profits of health insurance companies.

Some may argue that being cognizant of the structural violence that impacts our patients' lives, such as macroeconomic issues and healthcare delivery payment structures, is outside the duty and expertise of clinicians. We would posit that healthcare professionals have an ethical responsibility to address all determinants of health, particularly those which are embedded in the fabric of their professions. This neoliberal system has also failed to protect healthcare workers. Neoliberal profit-driven production models hindered manufacturing of PPE in preparation for a pandemic, directly endangering clinicians. One of the most incongruous demonstrations of a healthcare system built on profit-generation is the reports of healthcare workers losing their jobs due to large profit loss from the cancellation of elective surgeries and procedures during this pandemic.

The COVID-19 pandemic lays bare the inadequacies and instabilities inherent to healthcare delivery models that operate according to a neoliberal ethic. Trillions of dollars have been spent to keep stock markets afloat, yet a fraction of that has 
been spent to guarantee employment, income, or healthcare access, exacerbating already precarious socioeconomic situations for many. Pandemic preparedness was derailed when ventilator stockpiles were hindered by a corporation cancelling manufacturing contracts with the government due to their lack of profitability. ${ }^{4}$ The rhetoric of the federal government and others has unequivocally advocated for profit at the expense of human lives.

As we are witnessing, crises make deficiencies more glaring, and the COVID-19 pandemic is exacerbating pre-existing disparities. ${ }^{5}$ The neoliberal presumption that social services can be improved by creating markets for competition, then reducing governmental influence in those markets, has defined the course of healthcare provision in the USA for the past century. This inherently constructs a hierarchy whereby health services and health are concentrated among those of prior social privilege, be that economic, racial, immigration status, or other. This sharp reinforcement of inequality is formulated out of a fundamental tenet of neoliberalism: relying on free markets to allow people to procure the goods and services they need to survive. This is unethical because many will be unable to engage in those markets due to pre-existing inequalities and injustices. For example, racism exists in all domains of American society, and creating a free market for healthcare will necessarily prioritize the health of those most able to participate in the market - those of privilege. Indeed, profound racial disparities exist in COVID-19 infection rates and mortality, likely due to multiple direct causes - the root of which being structural racism.

Tying healthcare access to employment status becomes particularly problematic when public health necessitates the complete shutdown of whole industries, affecting millions of workers in the retail, food services, transportation, and entertainment sectors. Since the announcement of shelter-in-place and anti-congregation orders, the USA has seen the most filings for unemployment in a single week in recorded history. Without healthcare for all, mass unemployment becomes an even more threatening prospect as those who are infected without health insurance could be more likely to delay or avoid care, furthering spread and mortality.

Social distancing requires all individuals make personal sacrifices for the benefit of the many, a communitarian proposition that is the antithesis of the personal freedom neoliberalism fetishizes. The ways in which the COVID-19 pandemic has touched nearly every part of human life calls for a collectivist pursuit of public health and safety, and to continue after this crisis abates. The COVID-19 pandemic is an emergency exacerbated by the pre-existing, long-simmering healthcare crises in the USA that arose from neoliberal ideologies and policies. Immediate universal health insurance could blunt the worst of this pandemic, but we must not return to the failures of our current system when this storm passes. Large-scale healthcare reforms that ensure healthcare for all people, decouple capital generation from healthcare, and prioritize human rights will ensure a more ethical system and a healthier society for all of us.

Corresponding Author: Elizabeth Dzeng, MD, PhD, MPH; Department of Medicine, Division of Hospital Medicine, University of California, San Francisco, San Francisco, CA, USA (e-mail: Liz. dzeng@ucsf.edu).

Funding C.A. was supported by the National Center for Advancing Translational Sciences, National Institutes of Health, through UCSFCTSI Grant Number TL1 TR001871. The content is solely the responsibility of the authors and does not necessarily represent the official views of the NIH.

\section{Compliance with Ethical Standards:}

Conflict of Interest: None of the authors have any conflicts of interest to report.

\section{REFERENCES}

1. Tolbert J, Orgera K, Singer N, Damico A. Key Facts about the Uninsured Population. Kaiser Family Foundation. 2019. https://www.kff.org/uninsured/issue-brief/key-facts-about-the-uninsured-population/. Accessed on Apr 9, 2020.

2. Harvey D. A Brief History of Neoliberalism. Oxford, Oxford University Press: 2005.

3. Galvani AP, Parpia AS, Foster EM, Singer BH, Fitzpatrick MC. Improving the prognosis of health care in the USA. Lancet. 2020; https://doi.org/10.1016/S0140-6736(19)33019-3

4. Kulish N, Kliff S, Silver-Greenberg J. The U.S. Tried to Buld a New Fleet of Ventilators. The Mission Failed. New York Times. 2020. https://www. nytimes.com/2020/03/29/business/coronavirus-us-ventilator-shortage. html. Accessed on Mar 30, 2020.

5. Williams DR, Cooper LA. COVID-19 and Health Equity-A New Kind of "Herd Immunity". JAMA. 2020; https://doi.org/10.1001/jama.2020.8051

Publisher's Note: Springer Nature remains neutral with regard to jurisdictional claims in published maps and institutional affiliations. 